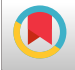

\title{
Prevalence of Antibiotic Resistance and Distribution of Virulence Factors in the Shiga Toxigenic Escherichia coli Recovered from Hospital
}

\section{Food}

\author{
Reza Ranjbar ${ }^{1,}$, Ali Seif $^{2}$ and Farhad Safarpoor Dehkordi ${ }^{3}$ \\ ${ }^{1}$ Molecular Biology Research Center, Systems Biology and Poisonings Institute, Baqiyatallah University of Medical Sciences, Tehran, Iran \\ ${ }^{2}$ Faculty of Veterinary Medicine, Shahrekord Branch, Islamic Azad University, Shahrekord, Iran \\ ${ }^{3}$ Halal Research Center of IRI, FDA, Tehran, Iran \\ "Corresponding author: Full Professor of Bacteriology, Molecular Biology Research Center, Systems Biology and Poisonings Institute, Baqiyatallah University of Medical \\ Sciences, Tehran, Iran. Tel: +98-9123048157, Email: ranjbar@bmsu.ac.ir
}

Received 2018 July 28; Revised 2019 May 07; Accepted 2019 May 09.

\begin{abstract}
Background: Regarding the presence of immunosuppressed patients in hospitals, hospital food must have a boost safety. Escherichia coli $\mathrm{O} 157$ is one of the prevalent causes of food-related poisoning.

Objectives: The current examination was done to assess the distribution of virulence factors and phenotypic analysis of antibiotic resistance of E. coli 0157 bacteria recovered from hospital food.

Methods: From April to August 2016, 200 hospital food samples were obtained and directly transported to the laboratory. Escherichia coli O157-positive bacteria were analyzed by disk diffusion and polymerase chain reaction (PCR).

Results: Nine out of 200 (4.50\%) samples harbored E. coli O157. Distribution of E. coli O157 in soup and gavage samples were $3 \%$ and $6 \%$, respectively. Stx1 (100\%), eaeA (100\%), and ehlyA (100\%) were the most frequently detected virulence genes. Escherichia coli O157 bacteria exhibited maximum prevalence of antibiotic resistance against tetracycline (100\%), gentamycin (100\%), ampicillin (100\%), mezlocillin (50\%), enrofloxacin (50\%), and trimethoprim (50\%). Distribution of resistance of E. coli O157 bacteria against more than six antibiotic agents was $11.11 \%$.

Conclusions: Gavage and soup samples may be sources of virulent and resistant E. coli O157. High presence of E. coli O157, simultaneous presence of multiple virulence genes, and resistance against animal-based antibiotics presented inadequacy of cooking time and temperature in processing of hospital foods.
\end{abstract}

Keywords: Virulence Factors, Antibiotic Resistance Properties, Hospital Food, Escherichia coli O157

\section{Background}

Due to the weakness and suppression of the immune system of hospital patients, hospital food should have acceptable hygienic safety. Amongst all known pathogenic bacteria responsible for food-borne disorders especially in public places, such as hospitals, Escherichia coli had an imperative role $(1,2)$. It is mainly responsible for outbreak of food poisonings in public places, including hospitals $(1,2)$. Escherichia coli are Gram-negative, non-sporulating, motile, flagellated, and rod shape bacteria with ability of growth in different types of foods under aerobic and anaerobic conditions. Shiga (vero) toxin (Stx) Escherichia coli (STEC) is a division of a noteworthy virulent group of the mentioned bacterium, known as enterohemorrhagic Escherichia coli (EHEC) (1, 3-5). Shiga toxin E. coli bacteria are responsible for rigorous medical disorders, such as hemorrhagic colitis (HC), lethal hemolytic uremic syndrome
(HUS), different kinds of diarrhea, and thrombotic thrombocytopenic purpura (TTP) $(1,4)$.

Outburst of food disorders are mainly related to certain serogroups and particularly $\operatorname{O157}(1,2,4-6)$. This serogroup is responsible for severe cases of food-borne gastrointestinal disorders (3-6). Some imperative virulence genes comprising intimin (eaeA), Shiga toxins (stx1 and stx2), and hemolysin ( $h l y A)$ are responsible for occurrence of $E$. coli colonization, adhesion, and invasion to intestinal walls (3-6). High prevalence of resistance in E. coli 0157 bacteria is an alternative imperative factor, which enhances the pathogenicity of bacteria. Inappropriately, 0157 E. coli bacteria related to food and clinical implications exhibited a high prevalence of resistance against normally used antibiotics (50\% to $100 \%$ ), especially tetracyclines, aminoglycosides, fluoroquinolones, macrolides, phenicols, and $\beta$ lactams (2-8). 


\section{Objectives}

Regarding the indeterminate role of E. coli O157 bacteria in foods of hospitals and lack of epidemiological surveys in this area in Iran, the current examination was performed to assess the frequency of virulence genes and phenotypic analysis of antibiotic resistance of E. coli $\mathrm{O} 157$ bacteria isolated from gavage and soup hospital food samples.

\section{Methods}

\subsection{Samples}

From April to August 2016, a total of 200 hospital food samples, such as gavage $(n=100)$ and soup $(n=100)$, were randomly collected from educational hospitals of Iran. Samples were directly transported to the laboratory in chillers with ice-packs. All gavage and soup samples displayed usual physical features and organoleptic characters.

\subsection{Escherichia coli 0157 Isolation and Identification}

For each sample, $25 \mathrm{~g}$ was homogenized and $1 \mathrm{~g}$ of the homogenate was added to $5 \mathrm{~mL}$ of buffered peptone water (Merck, Germany) and incubated. Cultures were speckled onto MacConkey sorbitol agar (Merck, Germany) and plates were incubated instantly at $37^{\circ} \mathrm{C}$. From each plate, five to ten distrusted colonies of E. coli bacteria (with both positive and negative sorbitol activities) were chosen and cultured another time on likely medium. Latex agglutination method was used for examination of 0157 antigen in the sorbitol-negative bacteria (Oxoid, Uk) (9). Isolates were further identified using biochemical tests, including Gram staining, cytochrome oxidase, Indole test, Methyl Red test, Voges-Proskauer test, citrate utilization (IMViC) test, and lysine decarboxylase test.

\subsection{Polymerase Chain Reaction Detection of Virulence Factors}

Bacteria were cultured another time in Luria-Bertani broth (Merck, Germany) at $37^{\circ} \mathrm{C}$. DNA was extracted from bacteria by DNA extraction kit (Thermo Fisher Scientific, Germany) rendering to the producer's guidelines. Table 1 displays the oligonucleotide primers and PCR circumstances applied for amplification of virulence genes $(10,11)$. DNA thermo-cycler (Flexrcycler ${ }^{2}$, Germany) was applied for this purpose. Fifteen microliters of the PCR products were introduced to $1.5 \%$ agarose gel electrophoresis (4).

\subsection{Antimicrobial Susceptibility Testing}

Mueller-Hinton agar (Merck, Germany) was applied for assess the pattern of antibiotic resistance using the simple disk diffusion technique. Antibiotic resistance of $E$. coli 0157 bacteria was studied against mezlocillin $(30 \mathrm{u})$, imipenem (30 u), ampicillin (10 u), cefotaxime (30 $\mu \mathrm{g})$, levofloxacin $(5 \mu \mathrm{g})$, gentamycin $(10 \mu \mathrm{g})$, ceftazidime $(30 \mu \mathrm{g})$, cotrimoxazole (30 $\mu \mathrm{g})$, cefepime (30 $\mu \mathrm{g})$, enrofloxacin (5 $\mu \mathrm{g})$, ciprofloxacin $(5 \mu \mathrm{g})$, sulfamethoxazole $(25 \mu \mathrm{g})$, tetracycline (30 u), trimethoprim (5 $\mu \mathrm{g})$, and chloramphenicol $(30 \mu \mathrm{g})$ (Oxoid, UK), using the Clinical and Laboratory Standards Institute guidelines (12).

\subsection{Statistical Analysis}

Data obtained from the experiments were transferred to Excel software. SPSS/21.0 software was applied for statistical analysis. Chi-square test and Fisher's exact two-tailed test were used to assess any significant relationship between parameters of the study. Numerical meaning was regarded at a $P$ value $<0.05$.

\section{Results}

Table 2 characterizes the distribution of E. coli $\mathrm{O} 157$ in hospital food samples. Nine out of 200 (4.50\%) hospital food samples were positive for $E$. coli O157. Distribution of $E$. coli 0157 in soup and gavage samples was $3 \%$ and $6 \%$, respectively. A statistically significant difference was observed for the distribution of E. coli O157 bacteria between soup and gavage samples $(\mathrm{P}<0.05)$.

Figure 1 and 2 represent the results of the gel electrophoresis of PCR products for studied virulence factors. Table 3 characterizes the distribution of virulence genes amongst the E. coli $\mathrm{O} 157$ bacteria isolated from hospital food samples. Stx1 (100\%), eaeA (100\%), and ehlyA $(100 \%)$ were the most routinely identified virulence genes amongst the E. coli $\mathrm{O} 157$ bacteria isolated from hospital food samples. Distribution of $s t x 2$ virulence gene was 22.22\%. Escherichia coli $\mathrm{O} 157$ bacteria isolated from soup samples had a higher distribution of $s t \times 2$ gene $(\mathrm{P}<0.05)$. All isolates were simultaneously positive for stx1, eaeA, and ehly genes (100\%).

Table 4 characterizes the antibiotic resistance pattern of $E$. coli $\mathrm{O} 157$ bacteria isolated from hospital food samples. Escherichia coli 0157 bacteria exhibited maximum incidence of resistance against tetracycline (100\%), gentamycin (100\%), ampicillin (100\%), mezlocillin (50\%), enrofloxacin (50\%), and trimethoprim (50\%) antibiotics. Distribution of resistance against imipenem (11.11\%) and chloramphenicol (22.22\%) was lower than other tested antibi- 


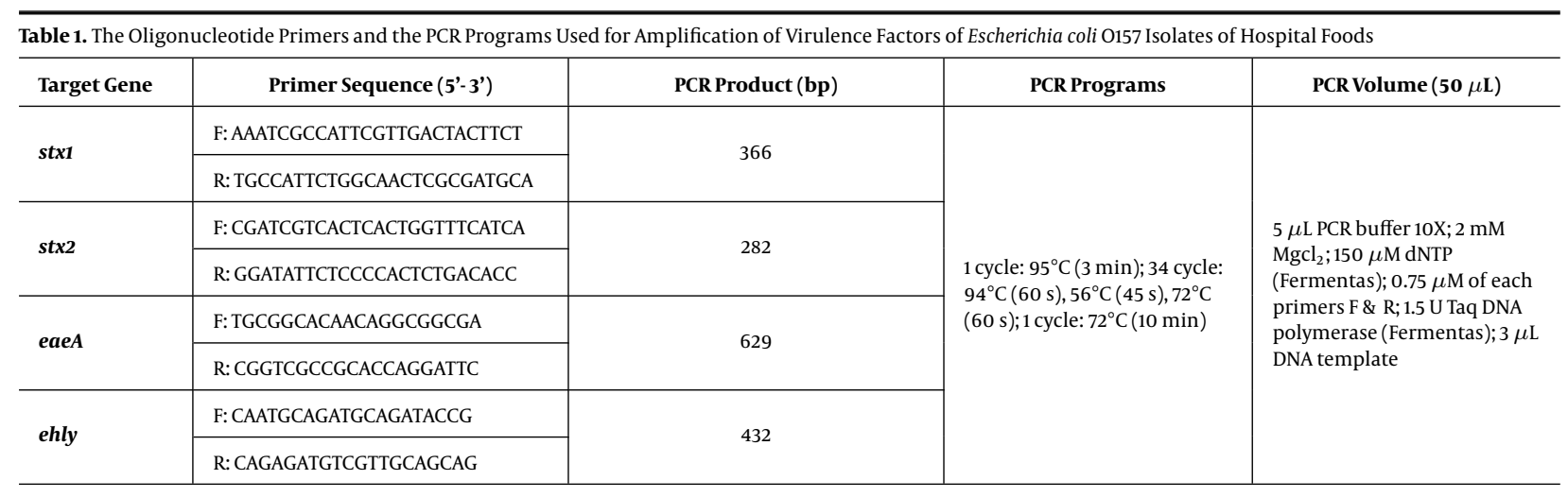

\begin{tabular}{lcc}
\hline \multicolumn{2}{l}{ Table 2. Total Distribution of Escherichia coli O157 in Hospital Food Samples } \\
\hline Types of Samples & No. Samples Collected & No Positive Strains (\%) \\
\hline Soup & 100 & $3(3)$ \\
Gavage & 100 & $6(6)$ \\
Total & 200 & $9(4.50)$ \\
\hline
\end{tabular}

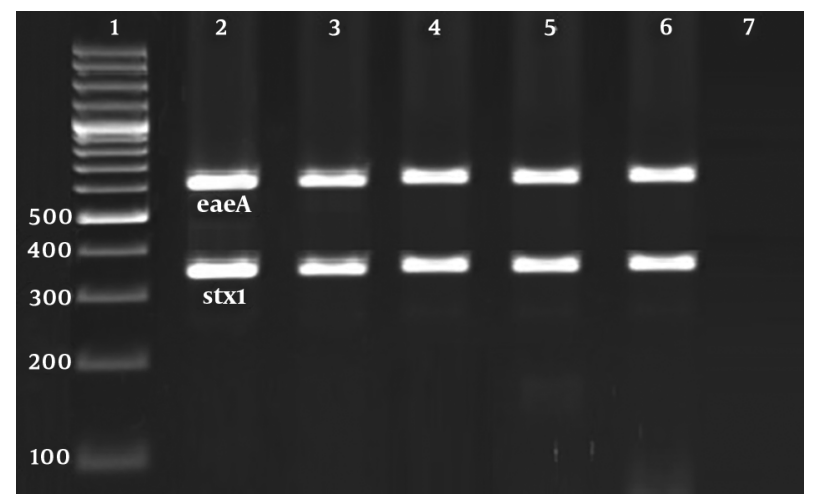

Figure 1. Results of the gel electrophoresis of PCR products for virulence factors. 1: 100 bp ladder (Thermo Fisher Scientific, Germany). 2 - 6: Positive samples for eaeA (629 bp) and stx1 (366 bp) virulence factors. 7: Positive control for each gene and 8: Negative control (Water PCR buffer (Thermo Fisher Scientific, Germany)).

otic agents. A statistically significant difference was observed for the distribution of antibiotic resistance between soup and gavage samples $(\mathrm{P}<0.05)$.

Figure 3 characterizes the distribution of multidrug resistant E. coli 157 bacteria isolated from hospital food samples. Multi-drug resistant E. coli $\mathrm{O} 157$ bacteria were determined as those, who had at least simultaneous resistance against three or more than three types of antibiotics. All E. coli $\mathrm{O} 157$ bacteria had at least resistance against three types of antibiotics (100\%), while distribution of resistance against more than six antibiotic agents was $11.11 \%$.

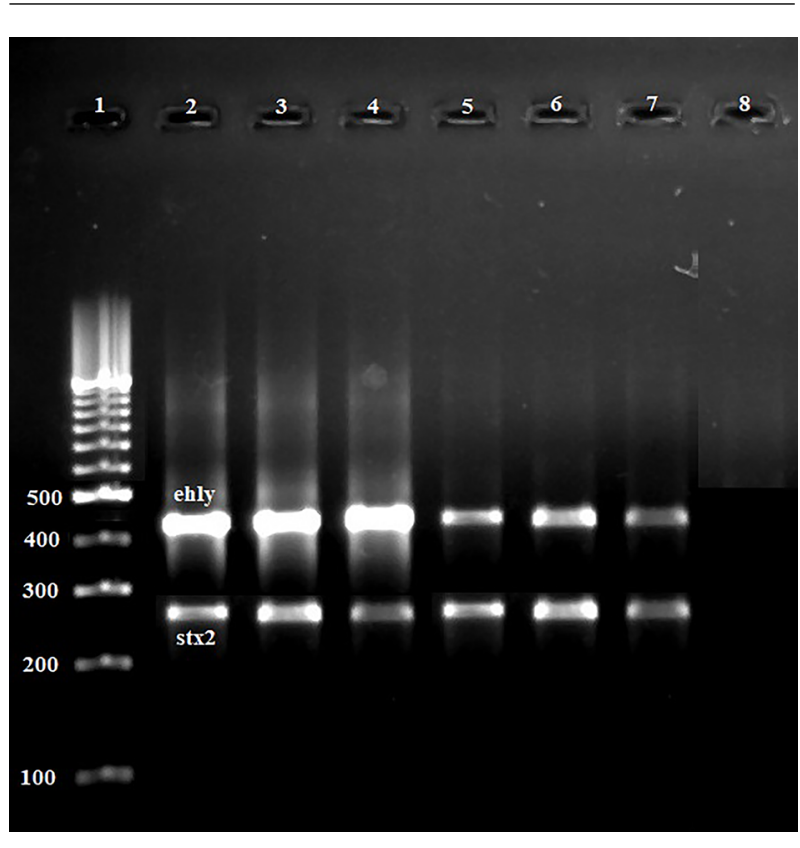

Figure 2. Results of the gel electrophoresis of PCR products for virulence factors. 1: 100 bp ladder (Thermo Fisher Scientific, Germany). 2 - 6: Positive samples for ehly (432 bp) and stx2 (282 bp) virulence factors. 7: Positive control for each gene and 8: Negative control (Water PCR buffer (Thermo Fisher Scientific, Germany)).

\section{Discussion}

Escherichia coli $\mathrm{O} 157$ is considered as one of the most dangerous causes of gastrointestinal disorders, along with the cause of most cases of food poisoning around the world $(13,14)$. Impact of $E$. coli $\mathrm{O} 157$ as a food-borne pathogen is increased in public places, such as dormitories and hostelry centers, especially hospitals. This is because of the presence of weak and immunosuppressed patients in hospitals, which need to use healthy and hygienic food.

The current research was done to evaluate the frequency of virulence genes and phenotypic pattern of antibiotic resistance of E. coli $\mathrm{O} 157$ bacteria recovered from 
Table 3. Distribution of Virulence Factors in Escherichia coli O157 Strains Isolated from Hospital Food Samples

\begin{tabular}{|c|c|c|c|c|c|c|}
\hline \multirow{2}{*}{ Types of Samples } & \multirow{2}{*}{ No. E. coli O157 Positive Samples } & \multicolumn{5}{|c|}{ Distribution of Virulence Genes (\%) } \\
\hline & & stx 1 & stx2 & eaeA & ehly & stxi+eaeA+ehly \\
\hline Soup & 3 & $3(100)$ & $1(33.33)$ & $3(100)$ & $3(100)$ & $3(100)$ \\
\hline Gavage & 6 & $6(100)$ & $1(16.66)$ & $6(100)$ & $6(100)$ & $6(100)$ \\
\hline Total & 9 & $9(100)$ & $2(22.22)$ & $9(100)$ & $9(100)$ & $9(100)$ \\
\hline
\end{tabular}

Table 4. Antibiotic Resistance Pattern of Escherichia coli O157strains Isolated from Hospital Food Samples

\begin{tabular}{|c|c|c|c|c|c|c|c|c|c|c|c|c|c|}
\hline \multirow{2}{*}{ Types of Samples (No. O157 Positive Samples) } & \multicolumn{13}{|c|}{ Antibiotic Resistance Pattern (\%) } \\
\hline & Tet $^{\mathrm{a}}$ & Cfz & Mez & Cfx & Gen & Cot & Enr & Cip & Imp & Amp & Tri & Lev & C3O \\
\hline Soup (3) & $3(100)$ & $1(33.33)$ & $1(33.33)$ & $1(33.33)$ & $3(100)$ & $2(66.66)$ & $3(100)$ & $1(33.33)$ & - & $3(100)$ & $2(66.66)$ & - & $2(66.66)$ \\
\hline Gavage (6) & $6(100)$ & $2(33.33)$ & $4(66.66)$ & $3(50)$ & $6(100)$ & $3(50)$ & 1(16.66) & $3(50)$ & $1(16.66)$ & $6(100)$ & $3(50)$ & $3(50)$ & - \\
\hline Total (9) & $9(100)$ & $3(33.33)$ & $5(55.55)$ & $4(44.44)$ & $9(100)$ & $5(55.55)$ & $4(44.44)$ & $4(44.44)$ & $1(11.11)$ & $9(100)$ & $5(55.55)$ & 3(33.33) & $2(22.22)$ \\
\hline
\end{tabular}

${ }^{\mathrm{a}}$ Tet: tetracycline (30 u/disk), Cfz: ceftazidime (30 $\mu \mathrm{g} /$ disk), Mez: mezlocillin (30 u/disk), Cfx: cefotaxime (30 $\mu \mathrm{g} /$ disk), Gen: gentamycin (10 $\left.\mu \mathrm{g} / \mathrm{disk}\right)$, Cot: cotrimoxazole (30 $\mu \mathrm{g} /$ disk), Enr: enrofloxacin (5 $\mu \mathrm{g} /$ disk), Cip: ciprofloxacin (5 $\mu \mathrm{g} /$ disk), Imp: imipenem (30 u/disk), Amp: ampicillin (10 u/disk), Tri: trimethoprim (5 $\mu \mathrm{g} /$ disk), Lev: levofloxacillin (5 $\mu \mathrm{g} /$ disk), C30: chloramphenicol (30 $\mu \mathrm{g} /$ disk).

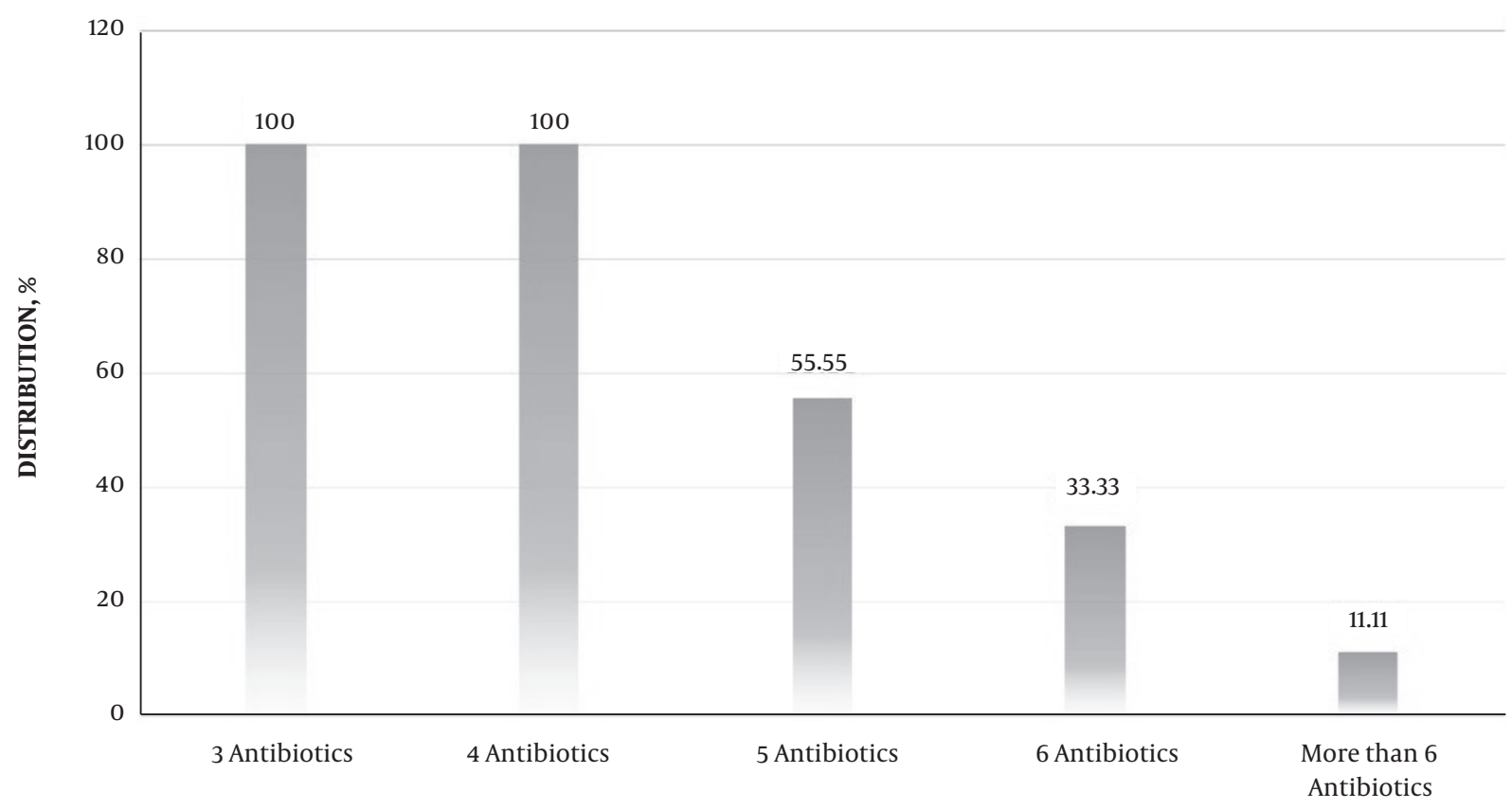

NUMBERS OF ANTIBIOTICS

Figure 3. Frequency of multidrug resistant Escherichia coli O157 bacteria recovered from foods of hospital. Multidrug resistant E. coli O157 strains were determined as those who had at least simultaneous resistance against 3 or more than 3 types of antibiotics.

hospital food. Apparently, the current examination is the initial description of the molecular characterization and antibiotic resistance properties of E. coli 0157 bacteria isolated from gavage and soup samples produced in hospitals. The current research established that $4.5 \%$ of hospital food samples were contaminated with E. coli 0157 bacteria, which was considerably high. The main reason for the high prevalence of E. coli $\mathrm{O} 157$ in hospital food samples is the presence of bacteria in raw meat and chicken used for preparation of soup and gavage samples and then their survival, probably due to the lack of adequate time and also temperature needed for catering and cooking of these ingredients.

The possibility of transmission of E. coli O157 from infected chefs and staffs of the hospital into the food samples is another important probable risk factor for con- 
siderable prevalence of E. coli $\mathrm{O} 157$ in hospital food samples. Higher distribution of E. coli $\mathrm{O} 157$ in gavage samples (6\%) compared with soup samples (3\%) is due to the fact that preparation of gavage samples requires handintervention of staffs of the hospital kitchen. Otherwise, preparation of gavage samples requires high hand manipulation, which increase the risk of microbial contamination. Moreover, liquid and watery basis of gavage samples makes them more prone to become infected with dangerous food-borne bacteria.

Initial investigation, which was conducted in this field, indicated that hospital food was a routine source of $E$. coli serotypes (15). Ranjbar et al. (1) reported that 39 out of 580 (6.72\%) hospital food samples were contaminated with $E$. coli and distribution of $\mathrm{O} 157$ serogroup was $25 \%$. Impact of food handlers in transmission of E. coli bacteria to food has been described before from USA (16) and Nigeria (17). Boost variances in the distribution of $E$. coli bacteria described in different researches may be due to differences in types of samples, way of sampling, method of experimentation, levels of hygiene, and as a final point topographical and geographical area, from which the food samples were collected.

The current research indicates that $E$. coli 0157 bacteria harbored high distribution of virulence factors and particularly stx1, eaeA, and ehlyA. The EHEC subtype of E. coli and mainly E. coli 0157 bacteria should simultaneously harbor stx1, eaeA, and ehlyA genes together. The current findings showed that simultaneous distribution of stx1, eaeA, and ehlyA genes together was $100 \%$. Boost distribution of these factors in E. coli 0157 bacteria disclosed their high pathogenicity for patients.

Concurrent presence of virulence genes in some E. coli O157 bacteria specified an imperative public health concern facing health care units and hospitals. Simultaneous presence of virulence genes has also been reported formerly in the E. coli bacteria isolated from diverse kinds of food samples in Iran (1, 3-8, 10, 11), Iraq (18), United States (19), and Nigeria (20). These genes are mostly related to bacterial linkage and attack the cells of gastric epithelium and also occurrence of diarrhea (21). Thus, their boost distribution in food samples of the current study guarantees the high pathogenicity of E. coli 0157 bacteria.

This study also suggested that E. coli $\mathrm{O} 157$ bacteria displayed high prevalence of resistance against extensive ranges of antibiotics and particularly tetracycline, gentamycin, ampicillin, mezlocillin, enrofloxacin, and trimethoprim. Furthermore, 11.11\% of E. coli 0157 bacteria harbored simultaneous resistance against more than six antibiotic agents. Unlawful and unselective prescription of antibiotics and inattentiveness to findings of the disk diffusion method in antibiotic prescription are the main factors causing boost prevalence of antibiotic resistance. The current research also established that occurrence of resistance against chloramphenicol in the studied E. coli O157 bacteria was 22.22\%. Extraordinary occurrence of resistance against this antibiotic was mostly due to the boost and unequal prescription of chloramphenicol in poultry farms in Iran and transmission of chloramphenicolresistant E. coli $\mathrm{O} 157$ bacteria from contaminated poultry meat to soup and gavage samples.

Another finding of the current study was that the $E$. coli O157 bacteria had extraordinary prevalence of resistance against animal-based antibiotics, which can indirectly support their animal origin. This part of the research was related to those of India (22) (extraordinary occurrence of resistance against amikacin, erythromycin, kanamycin cephalothin, and gentamicin antibiotics), South Africa (23) (extraordinary occurrence of resistance against gentamicin, ampicillin, and tetracycline antibiotic agents), Korea (24) (extraordinary occurrence of resistance against streptomycin, ampicillin, tetracycline, and amikacin antibiotics), and Mexico (25) (extraordinary occurrence of resistance against trimethoprim-sulfamethoxazole, ampicillin, cephalotine, and chloramphenicol antibiotics). Stewardson et al. (26) described that prevalence of resistance of E. coli bacteria against meropenem, gentamicin, ciprofloxacin, cotrimoxazole, and fosfomycin was $100 \%$, $90 \%, 87 \%, 79 \%$, and $98 \%$, respectively.

Extraordinary prevalence of resistance against tetracycline, ampicillin, gentamicin, mezlocillin, enrofloxacin, and trimethoprim was also reported from USA (27), China (28), and Iran (29). Boost prevalence of resistance against routine types of antibiotic agents has been described previously (30-43). Mashak (44) reported that prevalence of E. coli in raw meat, milk, and vegetables collected from Iran was $14 \%, 20 \%$, and $31.25 \%$, respectively. She showed that all of the E. coli $\mathrm{O} 157$ strains harbored simultaneous presence of stx1, eaeA, and ehly virulence genes, which was similar to the current report. She also showed that prevalence of resistance of STEC strains against ampicillin, gentamycin, tetracycline, and ciprofloxacin was 100\%, 90.47\%, $85.71 \%$ and $71.42 \%$, respectively.

In keeping with the high importance of the present research, there were some limitations, including low number of hospital food samples, low variation of hospital food samples, and finally high cost of the study experiment. Resistant food-borne pathogens, such as E. coli O157, methicillin-resistant Staphylococcus aureus (MRSA), Helicobacter pylori, and other bacterial agents are considered as important causes of outbreaks of food poisoning, especially in public places, such as hospitals (45-53). Proper 
cooking of raw foods, especially meat and chicken, and full compliance of principles of individual hygiene in kitchen of hospitals are the best ways to increase microbial quality and safety of hospital food samples, especially gavage and soup.

\subsection{Conclusions}

In conclusion, the current study recognized a high distribution of virulence genes and antibiotic resistance in $E$. coli $\mathrm{O} 157$ bacteria recovered from gavage and soup hospital foods. Gavage samples had a higher incidence of E. coli 0157 bacteria. Stx1, eaeA, and ehlyA virulence factors, resistance against ampicillin, gentamycin, and tetracycline and presence of multi-drug resistant bacteria were the most frequent characters in the E. coli $\mathrm{O} 157$ bacteria recovered from soup and gavage. Simultaneous presence of stx1, stx2, eaeA, and ehlyA virulence genes exhibits the boost pathogenicity of E. coli $\mathrm{O} 157$ bacteria. Presence of $\mathrm{O} 157$ bacteria, virulence factors, and animal-based antibiotics in soup and gavage posed inadequacy of cooking temperature and time used for preparation of foods in hospitals. It appears that there were no severe managements on the principles of food security in hospitals. Attention to the findings of disk diffusion method, and whole cooking of foods can diminish the risk of $E$. coli $\mathrm{O} 157$ bacteria in soup and gavage samples produced at hospitals.

\section{Acknowledgments}

Authors of the present investigation would like to acknowledge all staffs of the Molecular Biology Research Center, Systems Biology and Poisonings Institute, Baqiyatallah University of Medical Sciences, Tehran, Iran for their significant participation and technical supports.

\section{Footnotes}

Authors' Contribution: Reza Ranjbar and Farhad Safarpoor Dehkordi: Study design, PCR genetic alignment, writing, and drafting of the manuscript. Ali Seyf: Sample collection, culture-based identification, and statistical analysis.

Conflict of Interests: The authors state no conflicts of interest regarding the publication of the current paper.

Ethical Considerations: The research was permitted by the Moral Council of Research of the Baqiyatallah University of Medical Sciences, Tehran, Iran (96-2020). Confirmation of the current investigation and the certificates associated with sampling procedure were permitted by Reza Ranjbar (Endorsement Referee Quantity Med-96-3031). Financial Disclosure: There was no financial disclosure to report.
Funding/Support: This work was supported by the Baqiyatallah University of Medical Sciences, Tehran, Iran.

\section{References}

1. Ranjbar R, Masoudimanesh M, Dehkordi FS, Jonaidi-Jafari N, Rahimi E. Shiga (Vero)-toxin producing Escherichia coli isolated from the hospital foods; virulence factors, o-serogroups and antimicrobial resistance properties. Antimicrob Resist Infect Control. 2017;6:4. doi: 10.1186/s13756-016-0163-y. [PubMed: 28074125]. [PubMed Central: PMC5219770].

2. Safarpoor Dehkordi F, Gandomi H, Basti AA, Misaghi A, Rahimi E. Phenotypic and genotypic characterization of antibiotic resistance of methicillin-resistant Staphylococcus aureus isolated from hospital food.Antimicrob Resist Infect Control. 2017;6:104. doi:10.1186/s13756-0170257-1. [PubMed: 29034091]. [PubMed Central: PMC5628482].

3. Dehkordi FS, Yazdani F, Mozafari J, Valizadeh Y. Virulence factors, serogroups and antimicrobial resistance properties of Escherichia coli strains in fermented dairy products. BMC Res Notes. 2014;7:217. doi: 10.1186/1756-0500-7-217. [PubMed: 24708594]. [PubMed Central: PMC3983858].

4. Ranjbar R, Safarpoor Dehkordi F, Sakhaei Shahreza MH, Rahimi E. Prevalence, identification of virulence factors, O-serogroups and antibiotic resistance properties of Shiga-toxin producing Escherichia coli strains isolated from raw milk and traditional dairy products. Antimicrob Resist Infect Control. 2018;7:53. doi: 10.1186/s13756-018-0345-x. [PubMed: 29686859]. [PubMed Central: PMC5902837].

5. Hemmatinezhad B, Khamesipour F, Mohammadi M, Safarpoor Dehkordi F, Mashak Z. Microbiological investigation of O-serogroups, virulence factors and antimicrobial resistance properties of shiga toxin-producingescherichia coliisolated from Ostrich, Turkey and Quail meats. J Food Safety. 2015;35(4):491-500. doi:10.1111/jfs.12199.

6. Momtaz H, Dehkordi FS, Hosseini MJ, Sarshar M, Heidari M Serogroups, virulence genes and antibiotic resistance in Shiga toxin-producing Escherichia coli isolated from diarrheic and non-diarrheic pediatric patients in Iran. Gut Pathog. 2013;5(1):39. doi: 10.1186/1757-4749-5-39. [PubMed: 24330673]. [PubMed Central: PMC3866933].

7. Shahrani M, Dehkordi FS, Momtaz H. Characterization of Escherichia coli virulence genes, pathotypes and antibiotic resistance properties in diarrheic calves in Iran. Biol Res. 2014;47:28. doi: 10.1186/0717-6287 47-28. [PubMed: 25052999]. [PubMed Central: PMC4105491].

8. Momtaz H, Safarpoor Dehkordi F, Taktaz T, Rezvani A, Yarali S. Shiga toxin-producing Escherichia coli isolated from bovine mastitic milk: serogroups, virulence factors, and antibiotic resistance properties. Sci World J. 2012;2012:618709. doi: 10.1100/2012/618709. [PubMed: 23213293]. [PubMed Central: PMC3507047].

9. Dontorou C, Papadopoulou C, Filioussis G, Economou V, Apostolou I, Zakkas G, et al. Isolation of Escherichia coli O157:H7 from foods in Greece. Int J Food Microbiol. 2003;82(3):273-9. doi: 10.1016/S01681605(02)00313-6. [PubMed: 12593930].

10. Momtaz H, Farzan R, Rahimi E, Safarpoor Dehkordi F, Souod N Molecular characterization of Shiga toxin-producing Escherichia coli isolated from ruminant and donkey raw milk samples and traditional dairy products in Iran. Sci World J. 2012;2012:231342. doi: 10.1100/2012/231342. [PubMed: 22919299]. [PubMed Central: PMC3419413]

11. Momtaz H, Safarpoor Dehkordi F, Rahimi E, Ezadi H, Arab R. Incidence of Shiga toxin-producing Escherichia coli serogroups in ruminant's meat. Meat Sci. 2013;95(2):381-8. doi: 10.1016/j.meatsci.2013.04.051. [PubMed: 23747633]. 
12. CLSI. Performance standards for antimicrobial susceptibility testing. Twenty-second informational supplement M100-S21. Wayne, PA: Clinical and Laboratory Standards Institute (CLSI); 2012.

13. Disassa N, Sibhat B, Mengistu S, MuktarY, Belina D. Prevalence and antimicrobial susceptibility pattern of E. coli O157:H7 Isolated from traditionally marketed raw cow milk in and around Asosa Town, Western Ethiopia. Vet Med Int. 2017;2017:7581531. doi: 10.1155/2017/7581531. [PubMed: 28316862]. [PubMed Central: PMC5337877].

14. Pollari F, Christidis T, Pintar KDM, Nesbitt A, Farber J, Lavoie MC, et al. Evidence for the benefits of food chain interventions on E. coli 0157:H7/NM prevalence in retail ground beef and human disease incidence: A success story. Can J Public Health. 2017;108(1):e71-8. doi: 10.17269/cjph.108.5655. [PubMed: 28425902].

15. Muriana PM, Eager J, Wellings B, Morgan B, Nelson J, Kushwaha K. Evaluation of antimicrobial interventions against E. coli $\mathrm{O} 157: \mathrm{H} 7$ on the surface of raw beef to reduce bacterial translocation during blade tenderization. Foods. 2019;8(2). doi: 10.3390/foods8020080. [PubMed: 30791620]. [PubMed Central: PMC6406433].

16. Gutierrez-Rodriguez E, Gundersen A, Sbodio A, Koike S, Suslow TV. Evaluation of post-contamination survival and persistence of applied attenuated E. coli O157:H7 and naturally-contaminating E. coli O157:H7 on spinach under field conditions and following postharvest handling. Food Microbiol. 2019;77:173-84. doi: 10.1016/j.fm.2018.08.013. [PubMed: 30297048].

17. Ifeadike CO, Ironkwe OC, Adogu PO, Nnebue CC, Emelumadu OF, Nwabueze SA, et al. Prevalence and pattern of bacteria and intestinal parasites among food handlers in the Federal Capital Territory of Nigeria. Niger Med J. 2012;53(3):166-71. doi: 10.4103/0300-1652.104389. [PubMed: 23293419]. [PubMed Central: PMC3531038].

18. Othman R. Molecular detection of the virulence genes in escherichia coli isolated from healthy and diarrheic calves in Southern Iraq. Annual Res Rev Biol. 2018;26(6):1-10. doi: 10.9734/arrb/2018/40765.

19. Jay-Russell MT, Hake AF, Bengson Y, Thiptara A, Nguyen T. Prevalence and characterization of Escherichia coli and Salmonella strains isolated from stray dog and coyote feces in a major leafy greens production region at the United States-Mexico border. PLoS One. 2014;9(11). e113433. doi: 10.1371/journal.pone.0113433. [PubMed: 25412333]. [PubMed Central: PMC4239069]

20. Kabiru LM, Bello M, Kabir J, Grande L, Morabito S. Detection of pathogenic Escherichia coli in samples collected at an abattoir in Zaria, Nigeria and at different points in the surrounding environment. Int J Environ Res Public Health. 2015;12(1):679-91. doi: 10.3390/ijerph120100679. [PubMed: 25590145]. [PubMed Central: PMC4306886].

21. Melton-Celsa AR. Shiga toxin (Stx) classification, structure, and function. Microbiol Spectr. 2014;2(4):EHEC-24-2013. doi 10.1128/microbiolspec.EHEC-0024-2013. [PubMed: 25530917]. [PubMed Central: PMC4270005].

22. Mahanti A, Samanta I, Bandopaddhay S, Joardar SN, Dutta TK, Batabyal $S$, et al. Isolation, molecular characterization and antibiotic resistance of Shiga toxin-producing Escherichia coli (STEC) from buffalo in India. Lett Appl Microbiol. 2013;56(4):291-8. doi: 10.1111/lam.12048. [PubMed: 23350641].

23. Iweriebor BC, Iwu CJ, Obi LC, Nwodo UU, Okoh AI. Multiple antibiotic resistances among Shiga toxin producing Escherichia coli O157 in feces of dairy cattle farms in Eastern Cape of South Africa. BMC Microbiol. 2015;15:213. doi: 10.1186/s12866-015-0553-y. [PubMed: 26475706] [PubMed Central: PMC4609099].

24. Kang E, Hwang SY, Kwon KH, Kim KY, Kim JH, Park YH. Prevalence and characteristics of Shiga toxin-producing Escherichia coli (STEC) from cattle in Korea between 2010 and 2011.JVet Sci. 2014;15(3):369-79. doi: 10.4142/jvs.2014.15.3.369. [PubMed: 23820205]. [PubMed Central: PMC4178138]

25. Ramirez Castillo FY, Avelar Gonzalez FJ, Garneau P, Marquez Diaz
F, Guerrero Barrera AL, Harel J. Presence of multi-drug resistant pathogenic Escherichia coli in the San Pedro River located in the State of Aguascalientes, Mexico. Front Microbiol. 2013;4:147. doi: 10.3389/fmicb.2013.00147. [PubMed: 23785356]. [PubMed Central: PMC3683621].

26. Stewardson AJ, Renzi G, Maury N, Vaudaux C, Brossier C, Fritsch E, et al. Extended-spectrum beta-lactamase-producing Enterobacteriaceae in hospital food: A risk assessment. Infect Control Hosp Epidemiol. 2014;35(4):375-83. doi:10.1086/675609. [PubMed: 24602942].

27. Tadesse DA, Zhao S, Tong E, Ayers S, Singh A, Bartholomew MJ, et al. Antimicrobial drug resistance in Escherichia coli from humans and food animals, United States, 1950-2002. Emerg Infect Dis. 2012;18(5):7419. doi: 10.3201/eid1805.111153. [PubMed: 22515968]. [PubMed Central: PMC3358085].

28. Yassin AK, Gong J, Kelly P, Lu G, Guardabassi L, Wei L, et al. Antimicrobial resistance in clinical Escherichia coli isolates from poultry and livestock, China. PLoS One. 2017;12(9). e0185326. doi: 10.1371/journal.pone.0185326. [PubMed: 28934348]. [PubMed Central: PMC5608385].

29. Akhtardanesh B, Ghanbarpour R, Ganjalikhani S, Gazanfari P. Determination of antibiotic resistance genes in relation to phylogenetic background in Escherichia coli isolates from fecal samples of healthy pet cats in Kerman city. Vet Res Forum. 2016;7(4):301-8. [PubMed: 28144421]. [PubMed Central: PMC5251352]

30. Atapoor S, Safarpoor Dehkordi F, Rahimi E. Detection of Helicobacter pylori in various types of vegetables and salads. Jundishapur J Microbiol. 2014;7(5). e10013. doi: 10.5812/jjm.10013. [PubMed: 25147709]. [PubMed Central: PMC4138632].

31. Safarpoor Dehkordi F, Parsaei P, Saberian S, Moshkelani S, Hajshafiei $\mathrm{P}$, Hoseini S. Prevalence study of Theileria annulata by comparison of four diagnostict techniques in southwest Iran. Bulg J Vet Med. 2012;15(2):123-30.

32. Rahimi E, Sepehri S, Safarpoor Dehkordi F, Shaygan S, Momtaz H. Prevalence of yersinia species in traditional and commercial dairy products in Isfahan province, Iran. Jundishapur J Microbiol. 2014;7(4). e9249. doi: 10.5812/jjm.9249. [PubMed: 25147698]. [PubMed Central: PMC4138625].

33. Momtaz H, Davood Rahimian M, Safarpoor Dehkordi F. Identification and characterization of Yersinia enterocolitica isolated from raw chicken meat based on molecular and biological techniques. J Appl Poult Res. 2013;22(1):137-45. doi: 10.3382/japr.2012-00549.

34. Safarpoor Dehkordi F, Barati S, Momtaz H, Hosseini Ahari SN, Nejat Dehkordi S. Comparison of shedding, and antibiotic resistance properties of listeria monocytogenes isolated from milk, feces, urine, and vaginal secretion of Bovine, Ovine, Caprine, Buffalo, and Camel Species In Iran. Jundishapur J Microbiol. 2013. doi:10.5812/jjm.6616.

35. Ghorbani F, Gheisari E, Safarpoor Dehkordi F. Genotyping of vacA alleles of Helicobacter pylori strains recovered from some Iranian food items. Trop J Pharm Res. 2016;15(8):1631. doi: 10.4314/tjpr.v15i8.5.

36. Dehkordi FS, Khamesipour F, Momeni M. Brucella abortus and Brucella melitensis in Iranian bovine and buffalo semen samples: The first clinical trial on seasonal, Senile and geographical distribution using culture, conventional and real-time polymerase chain reaction assays. Kafkas Univ Vet Fak Dergisi. 2014;20(6):821-8. doi: 10.9775/kvfd.2014.10827.

37. Safarpoor Dehkordi F, Haghighi N, Momtaz H, Rafsanjani MS, Momeni M. Conventional vs real-time PCR for detection of bovine herpes virus type 1 in aborted bovine, buffalo and camel foetuses. Bulg J Vet Med. 2013;16(2):102-11.

38. Nejat S, Momtaz H, Yadegari M, Nejat S, Safarpour Dehkordi F, Khamesipour F. Seasonal, geographical, age and breed distributions of equine viral arteritis in Iran. Kafkas Univ Vet Fak Derg. 2015;21(1):111-6. doi: 10.9775/kvfd.2014.11934.

39. Dehkordi FS, Valizadeh Y, Birgani TA, Dehkordi KG. Prevalence study 
of Brucella melitensis and Brucella abortus in cow's milk using dot enzyme linked immuno sorbent assay and duplex polymerase chain reaction. J Pure Appl Microbiol. 2014;8:1065-9.

40. Rahimi E, Yazdanpour S, Safarpoor Dehkordi F. Detection of Toxoplasma gondii antibodies in various poultry meat samples using enzyme linked immuno sorbent assay and its confirmation by polymerase chain reaction. J Pure Appl Microbiol. 2014;8(1):421-7.

41. Hasanpour Dehkordi A, Khaji L, Sakhaei Shahreza MH, Mashak Z, Safarpoor Dehkordi F, Safaee Y, et al. One-year prevalence of antimicrobial susceptibility pattern of methicillin-resistant Staphylococcus aureus recovered from raw meat. Trop Biomed. 2017;34(2):396-404.

42. Madahi H, Rostami F, Rahimi E, Safarpoor Dehkordi F. prevalence of enterotoxigenic staphylococcus aureus isolated from chicken nugget in Iran. Jundishapur J Microbiol. 2014;7(8). e10237. doi: 10.5812/jjm.10237. [PubMed: 25485044]. [PubMed Central: PMC4255206].

43. Momtaz H, Dehkordi FS, Rahimi E, Asgarifar A, Momeni M. Virulence genes and antimicrobial resistance profiles of Staphylococcus aureus isolated from chicken meat in Isfahan province, Iran. J Appl Poult Res. 2013;22(4):913-21. doi: 10.3382/japr.2012-00673.

44. Mashak Z. Virulence genes and phenotypic evaluation of the antibiotic resistance of vero toxin producing escherichia coli recovered from milk, meat, and vegetables. Jundishapur J Microbiol. 2018;11(5). doi: $10.5812 / j j m .62288$.

45. Abdolmaleki Z, Mashak Z, Safarpoor Dehkordi F. Phenotypic and genotypic characterization of antibiotic resistance in the methicillinresistant Staphylococcus aureus strains isolated from hospital cockroaches. Antimicrob Resist Infect Control. 2019;8:54. doi: 10.1186/s13756019-0505-7. [PubMed: 30911380]. [PubMed Central: PMC6416839].

46. Safarpoor Dehkordi F, Basti AA, Gandomi H, Misaghi A, Rahimi E. Pathogenic Staphylococcus aureus in hospital food samples; prevalence and antimicrobial resistance properties. J Food Safety. 2018;38(6). e12501. doi: 10.1111/jfs.12501.

47. Ranjbar R, Yadollahi Farsani F, Safarpoor Dehkordi F. ntimicrobial re- sistance and genotyping of vacA, cagA, and iceA alleles of the Helicobacter pylori strains isolated from traditional dairy products. JFood Safety. 2018;39(2). e12594. doi: 10.1111/jfs.12594

48. Ranjbar R, Farsani FY, Dehkordi FS. Phenotypic analysis of antibiotic resistance and genotypic study of the vacA, cagA, iceA, oipA and babA genotypes of the Helicobacter pylori strains isolated from raw milk. Antimicrob Resist Infect Control. 2018;7:115. doi: 10.1186/s13756-018-0409y. [PubMed: 30288255]. [PubMed Central: PMC6162967].

49. Dormanesh B, Safarpoor Dehkordi F, Hosseini S, Momtaz H, Mirnejad R, Hoseini MJ, et al. Virulence factors and o-serogroups profiles of uropathogenic Escherichia coli isolated from Iranian pediatric patients. Iran Red Crescent Med J. 2014;16(2). e14627. doi: 10.5812/ircmj.14627. [PubMed: 24719745]. [PubMed Central: PMC3965878].

50. Mousavi S, Dehkordi FS, Rahimi E. Virulence factors and antibiotic resistance of Helicobacter pylori isolated from raw milk and unpasteurized dairy products in Iran. J Venom Anim Toxins Incl Trop Dis 2014;20:51. doi: 10.1186/1678-9199-20-51. [PubMed: 25873940]. [PubMed Central: PMC4396062]

51. Dehkordi FS, Borujeni MR, Rahimi E, Abdizadeh R. Detection of Toxoplasma gondii in raw caprine, ovine, buffalo, bovine, and camel milk using cell cultivation, cat bioassay, capture ELISA, and PCR methods in Iran. Foodborne Pathog Dis. 2013;10(2):120-5. doi: 10.1089/fpd.2012.1311. [PubMed: 23441913].

52. Momtaz H, Karimian A, Madani M, Safarpoor Dehkordi F, Ranjbar R, Sarshar M, et al. Uropathogenic Escherichia coli in Iran: Serogroup distributions, virulence factors and antimicrobial resistance properties. Ann Clin Microbiol Antimicrob. 2013;12:8. doi: 10.1186/1476-0711-12-8. [PubMed: 23627669]. [PubMed Central: PMC3651382].

53. Momtaz H, Dehkordi FS, Rahimi E, Asgarifar A. Detection of Escherichia coli, Salmonella species, and Vibrio cholerae in tap water and bottled drinking water in Isfahan, Iran. BMC Public Health. 2013;13:556. doi: 10.1186/1471-2458-13-556. [PubMed: 23742181]. [PubMed Central: PMC3703282]. 